\title{
PRIMENA KVIZA DOMENSKOG ZNANJA UZ POMOĆ SPHERO ROBOTA U OBRAZOVANJU
}

\section{APPLICATION OF THE DOMAIN KNOWLEDGE QUIZ WITH THE HELP OF SPHERO ROBOT IN EDUCATION}

\author{
Dejan Stojkić, Fakultet tehničkih nauka, Novi Sad
}

\begin{abstract}
Oblast - ELEKTROTEHNIKA I RAČUNARSTVO
Kratak sadržaj - Postoje brojna istraživanja koja govore o tome kako deca u mlađim uzrastima dosta brže uče kroz igru. Tako da smo mi putem Sprk+ robota i desktop igre pokušali da kviz koji je vezan za domenska znanja koja se uče u školi učinimo što zanimljivijim. Istraživačke studije $u$ razvojnoj $i$ kognitivnoj psihologiji ukazuju na to da su uticaji na životnu sredinu važni tokom ranih godina razvoja $i$ da nedostatak neophodnih stimulacija $u$ vezi sa djetetovim razvojem dovodi do toga da djete ne dostigne svoj puni potencijal. U ovom radu su opisane dvije aplikacije koje su u formatu kviza. Prva aplikacija predstavlja kviz koji poseduje određenu grupu pitanja na osnovu koga robot sphero (SPRK+) vrši kretanje. Na osnovu tačnih odgovora iz date aplikacije vrši se pomeranje robota putem sphero EDU aplikacije. U Sphero EDU aplikaciji smo kreirali programe upotrebom javascript programskog jezika. Robot se kreće po ručno napravljenoj mapi koju smo prilagodili određenom domenu znanja. Druga aplikacija predstavlja desktop igru u formatu kviza razvijena putem WPF $i$ OpenGL gde imamo virtualnu mapu na kojoj se kreće $3 D$ objekat na osnovu odgovora iz date igre .
\end{abstract}

Ključne reči: Savremene obrazovne tehnologije, Kviz, Sphero SPRK+

\begin{abstract}
There is a wealth of research showing that children at a younger age learn much faster through play. So, through Sprk + robots and a desktop game, we tried to make the domain knowledge quiz we learn at school as interesting as possible. Research studies in developmental and cognitive psychology indicate that environmental impacts are important during the early years of development and that the lack of necessary stimuli related to the child's development causes the child to reach his or her full potential. This paper describes two applications that are in quiz format. The first application is a quiz that has a specific set of questions on the basis of which the robot sphero $(S P R K+)$ moves. So, based on the correct answers from a given application, the robot is moved through a sphero EDU application. In the Sphero EDU application, we have created programs using the javascript programming language. The robot moves around a handmade folder that we customize to a specific domain of knowledge. The second application is a desktop game in quiz format developed through WPF and OpenGL where we have a virtual map on which a $3 D$ object moves based on the answers from a game.
\end{abstract}

Keywords: Modern Educational Technologies, Quiz, Sphero SPRK +

\section{NAPOMENA:}

Ovaj rad proistekao je iz master rada čiji mentor je bio dr Aleksandar Kupusinac, van. prof.

\section{UVOD}

Sa razvojem tehnologije dolazimo do mogućnosti razvoja mnogih grana industrije ali i obrazovanja. U vreme kada deca od ranih godina imaju dodira sa računarom i pametnim uređajima i sama rasprostranjenost i dostupnost interneta teraju roditelje da neprestano brinu o upotrebi i načinu korištenja kompjutera od strane dece. Danas je sve veća i veća potreba za primenom tehnologije i olakšica koje tehnologija omogućava prilikom rešavanja određenih problema. Tako sam razvoj modernog doba ima i prednosti i mane. Da bi iskoristili prednosti modernog doba i što više zainteresovali decu za učenjem pokušavamo upotrebiti prednosti tehnologije i računara za efikasnije i zanimljivije izvođenja nastave.

Tako da ovo rešenje u obliku kviza na čije odgovore imamo posledicu kretanja robota i posebnu interaktivnu igru u formatu kviza može biti interesantno za razne oblasti i predmete koji se izučavaju u školama. Putem ovakvih kvizova deca se više interesuju i stvaraju želju za takmičenjem ko će imati više tačnih odgovora i ko će biti brži. Aplikacija, odnosno kviz, je razvijen u React [6] okruženju sa četiri pitanja po pet ponuđenih odgovora od kojih je samo jedan tačan. Kviz se sastoji iz četiri grupe pitanja. Prva grupa pitanja predstavlja laka pitanja ako su uspešno pređena onda je to ocjena dva. Druga grupa pitanja predstavlja malo teža pitanja za ocjenu tri. Treća grupa pitanja su još teža pitanja za ocjenu četiri i poslednja grupa pitanja koja su najteža a za ocjenu pet. Pitanja iz svih grupa su vezana za isti domen znanja samo su poredana po grupama i po težini kako bi pomogli nastavniku/učitelju pri ocjenjivanju.

\section{MOTIVACIJA}

Postoje brojna istraživanja koja govore o tome kako deca u mlađim uzrastima dosta brže uče kroz igru. Tako da vremenom na svetskom tržištu imamo sve više i više igračaka koje u suštini služe za učenje. Tako da smo mi putem Sprk+ robota pokušali da kviz koji je vezan za domenska znanja koja se uče u školi učinimo što zanimljivijim. Istraživačke studije $u$ razvojnoj i kognitivnoj psihologiji ukazuju na to da su uticaji na životnu sredinu važni tokom ranih godina razvoja i da nedostatak neophodnih stimulacija vezanih za djetetov razvoj dovodi do toga da djete ne dostigne svoj puni potencijal. Dakle, obrazovanje u ranim danima djetinjstva je od velikog značaja za mnoge aspekte djetetovog razvoja, a istraživači predlažu naučno obrazovanje treba početi u ranim godinama školovanja [1]. Postoji nekoliko 
razloga za početak podučavanja nauke tokom ranog detinjstva. Prvo, deca imaju prirodnu tendenciju u posmatranju i razmišljanju o prirodi [2].

Mala deca su motivisana da istraže svet oko sebe i rana naučna iskustva mogu iskoristiti ovu sklonost. Razvojno odgovarajuće angažovanje, sa kvalitetom iskustva učenja nauke je od vitalnog značaja za pomoć deci da razumeju svet, prikupe, organizuju informacije, primenjuju, testiraju ideje i razvijaju pozitivne stavove prema nauci. Kvalitetna iskustva učenja nauke pružaju solidnu osnovu za kasniji razvoj naučnih koncepata sa kojma će se deca susresti tokom njihovog akademskog života [3]. Ova fondacija pomaže studentima da konstruišu razumevanje ključnih naučnih koncepata i omogućava budućnost učenje više apstraktnih ideja (Reynolds \& Walberg, 1991). Angažovanje naučnih iskustava omogućava razvoj i naučno razmišljanje.

Podrška deci dok razvijaju naučno razmišljanje tokom ranog detinjstva mogu lako dovesti do toga da prenose svoje sposobnosti razmišljanja na druge akademske domene koji mogu značajno uticati na njihova akademska dostignuća i njihov smisao samoefikasnosti [3].

\section{SPHERO}

Sphero je sferna robot igračka koju je dizajnirala Sphero kompanija. To je bela kugla umotana u polikarbonatnu plastiku, sposobna da se okrene, menja boje, pokreće programe i kontroliše se pametnim telefonom ili tabletom. Sphero SPRK+ i drugi roboti koje je razvio Sphero koriste iste metode za komunikaciju i navigaciju, tako da programi razvijeni za jednog robota obično rade na svim Sphero robotima. Sphero roboti mogu da se kotrljaju za datu brzinu u određnom vremenu kod SPRK postoje dve led diode koje svetle u bilo kojoj zadatoj boji.

Unutrašnji senzori Sphero robota uključuju IMU i lokator. Omogućeno je bluetooth povezivanje sa uređajima kao što su iPads, iPhone,Android telefoni i tableti. Sphero je pokrenuo SPRK obrazovanje kako bi podržao nastavnike, roditelje i decu koristeći Sphero da nauče programiranje, robotiku i matematiku na zabavan, interaktivan način [4]. Sphero SPRK aplikacija također uključuje OVAL, programski jezik zasnovan na $\mathrm{C}$-u. Deca mogu da nauče da programiraju robota sa blokovima, a zatim evoluiraju do kodiranja pomoću OVAL-a, što može pomoći u upoznavanju sa načinima rada $\mathrm{C}, \mathrm{C}++$, Python, Ruby i drugih jezika.

Sphero EDU SPRK aplikacija omogućava korištenje OVAL-a za programiranje Sphero robota. Drugi koriste blokove za kreiranje i definiranje koraka. Blokovi predstavljaju ugrađene komande koje mi u suštini slažemo po želji i robot ih izvršava u nizu jednu za drogom.

Mi nažalost nismo uspeli da iskoristimo javascript biblioteku i njen API kako bi uspostavili vezu sa sprk+ robotom, pokušali smo na svim operativnim sistemima ali za verziju sprk+ nije moguće na taj način konektovati se zbog veće zaštite i zatvorenosti samog uređaja. Zbog hardverskih (tehničkih) problema koristili smo Sphero EDU aplikaciju koja nas je ograničavala za par funkcionalnosti. Zbog hardverskih problema i ograničenosti Sphero Edu aplikacije nismo mogli u real-time režimu da zadajemo naredbe koje proizilaze iz kviza.
Jedini način je bio da nakon što korisnik odgovori na sva pitanja pošaljemo date informacije Sphero EDU aplikaciji putem email-a sa datim informacijama ispitivaču koji bi u zavisnosti od dobijenih informacija pokrenuo određeni modul.

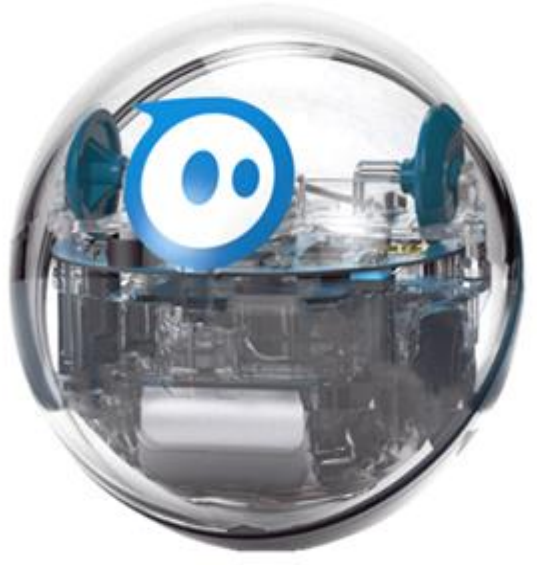

Slika 3.1: Sphero SPRK+ robot

\section{IMPLEMENTACIJA KVIZA SA ROBOTOM}

Izrada same aplikacije kviza zasniva se na kreiranju 4 grupe pitanja koja raspodeljena po težini. Za svako pitanje ponuđeno je pet odgovora od kojih je samo jedan tačan. Omogućeno je da se kviz može prilagoditi bilo kom domenu znanja što utiče na generičnost kviza i olakšava upotrebu nastavnicima i profesorima. Aplikacije je pre svega namenjena deci uzrasta osnovne škole od 5 . do 8 . razreda tako da imamo četiri grupe pitanja. Prva grupa pitanja je vezana za biljke. Kandidat prolazi kroz različite podoblasti ove oblasti i pokazuje svoje znanje.U drugoj oblasti su pitanja vezana za životinje.Treća grupa je vezana za izučavanje čoveka pa su pitanja prilagođena tom domenu.Četvrta grupa, koja je namenjena 8. razredu.

Ovaj deo aplikacije je napisan u react, javascript okruženju. React nam pruža veliku slobodu prilikom konstrukcije ovakvog rešenja i uz pomoć njega uspevamo da na jednostavan način kreiramo kviz sa svim reaktivnim komponentama. Pitanja su predstavljena u obliku json fajla gde je moguće izmeniti oblast i pitanja po potrebi. Tako da je u budućnosti moguća promena domena pitanja i samim tim rešenje postaje dinamičnije.

Ovaj deo aplikacije je napisan u react, javascript okruženju. React nam pruža veliku slobodu prilikom konstrukcije ovakvog rešenja i uz pomoć njega uspevamo da na jednostavan način kreiramo kviz sa svim reaktivnim komponentama. Pitanja su predstavljena u obliku json fajla gde je moguće izmeniti oblast i pitanja po potrebi. Tako da je u budućnosti moguća promena domena pitanja i samim tim rešenje postaje dinamičnije. Drugi deo implementacije je vezan za programiranje robota odnosno kretanja robota i dodavanje raznih specijalnih efekata $\mathrm{i}$ zvukova u zavisnosti od kombinacije odgovora.

Zbog problema sa hardverom odnosno nemogućnosti povezivanja u real-time režimu. Napravili smo neophodan broj modula odnosno odvojenih programa u Sphero Edu aplikaciji koji se pokreću u zavisnosti od krajnjegishoda. Postoji 15 modula, 15 JavaScript skripti koje su vezane za sve moguće ishode. 
Jedna skripta predstavlja ishod u kome je učenik odgovorio samo na prvo pitanje tačno. Svaka skripta se pokreće u odnosu na broj tačnih odgovora i u zavisnosti od rednog broja tačnih odgovora.

Obuhvaćene su sve mogućnosti čak i da učenik ne da ni jedan tačan odgovor. Neophodno je pre pokretanja programa pravilno kalibrisati robota da bi potpuno ispravno izvršio predviđenu skriptu. U osnovi svake skripte se nalaze naredbe kako će se robot kretati po mogućim poljima na mapi.

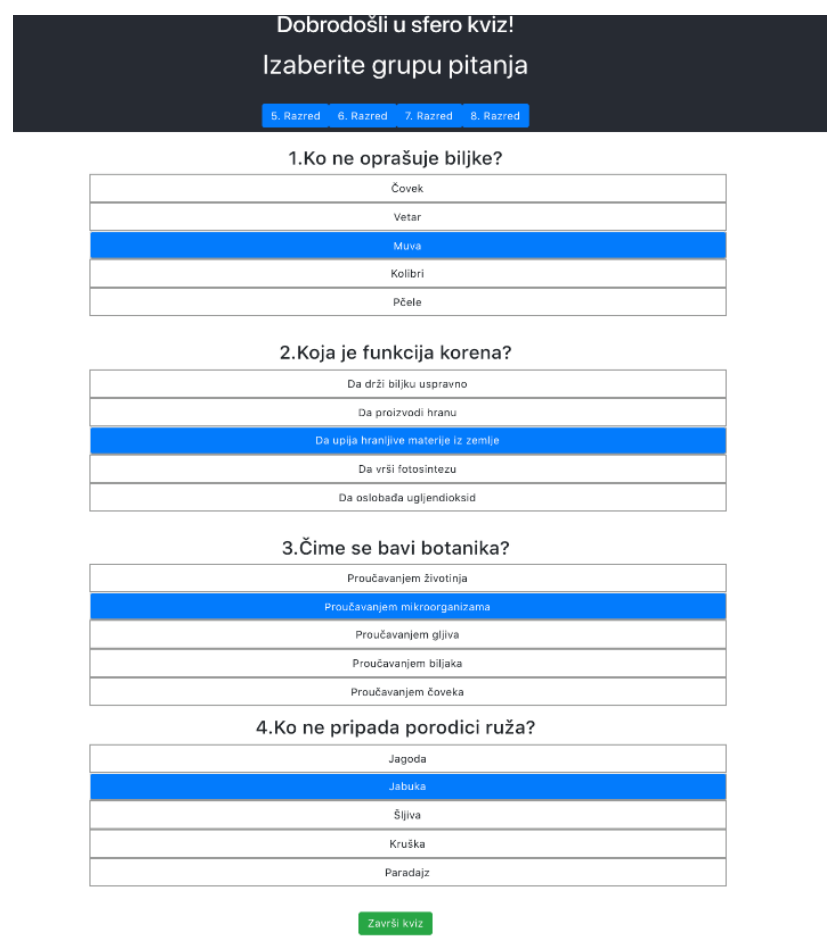

Slika 4.1: Kviz sa ponuđenim pitanjima

$\mathrm{Na}$ početku svakog modula (skripte) imamo uvodnu euforičnu melodiju koja dočarava početak avanture odnosno kviza i na kraju melodiju koja opisuje kraj avanture date runde koja može biti sretna ili tužna melodija u zavisnosti od tačnih odgovora. Ako su svi odgovori tačni onda je sretna melodija na kraju u suprotnom je tužna.

Nakon uvodne melodije čuje se efekat poletanja aviona sa piste pa se robot kreće ako je tačan odgovor i postepeno menja boju iz plave u zelenu ako je tačan odgovor i čuje se zvuk koji se obično koristi kod kvizova kako bi dočarali tačan odgovor i nakraju svakog pitanja ide akcija koja na engleskom govori da li je tačan odgovor.

Ako je netačan odgovor robot ide u jamu ili ne pomera se ako je već u njoj, boja postepeno prelazi iz trenutne boje $u$ crvenu boju i čuje se zvuk koji se obično koristi da bi opisali netačan odgovor, na kraju poslednja akcija vezana za to pitanje jeste glas koji na engleskom govori da je odgovor na dato (prvo,drugo itd..) pitanje ne tačan.

Treći segment implementacije vezan je za kreiranje same mape po kojoj se robot kreće. Na hamer dimenzije $100 \times 70 \mathrm{~cm}$ smo prvo odredili na kom mestu će se nalaziti start polje iz kog se robot kreće nakon ispravnog kalibrisanja. Zatim smo odredili polja koja predstavljaju prvo, drugo, treće i četvrto pitanje. Ako je odgovor tačan robot ide na dato polje $u$ suprotnom se vraća $u$ start odnosno u jamu.

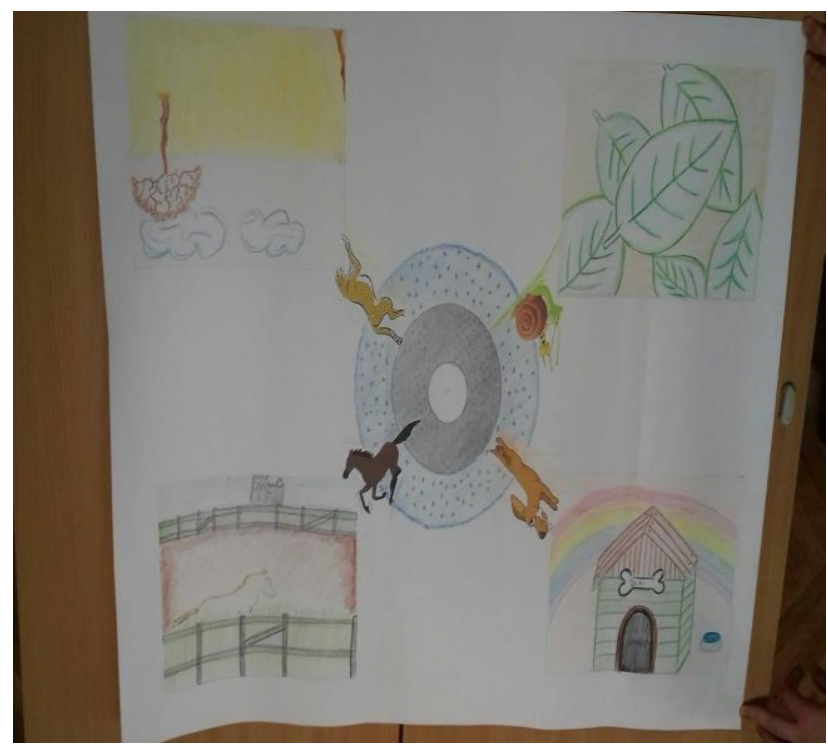

Slika 4.2: Ručno napravljena mape

\section{IMPLEMENTACIJA IGRE U FORMATU KVIZA}

Ovaj kviz predstavlja igru gde postoje dve vrste korisnika pofesori i učenici. Profesori imaju dodatne mogućnosti u odnosu na učenike. Prilikom prijavljivanja na aplikaciju na stranici za logovanje bira se vrsta korisnika.

\section{Dobrodosli}

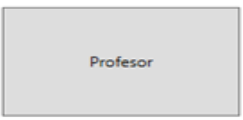

\section{Slika 5.1}

Logovanje je jednostavno realizovano trudeći se da bude slično kao logovanje na sistemu, nešto što je većini poznato. Naravno da bi se ulogovali korisnici koristi svoje ime i prezime sa šifrom. Šifre su heširane putem Bcrypt algoritma [5]. To nam omogućava sigurnost u slučaju da neko provali u bazu podataka.

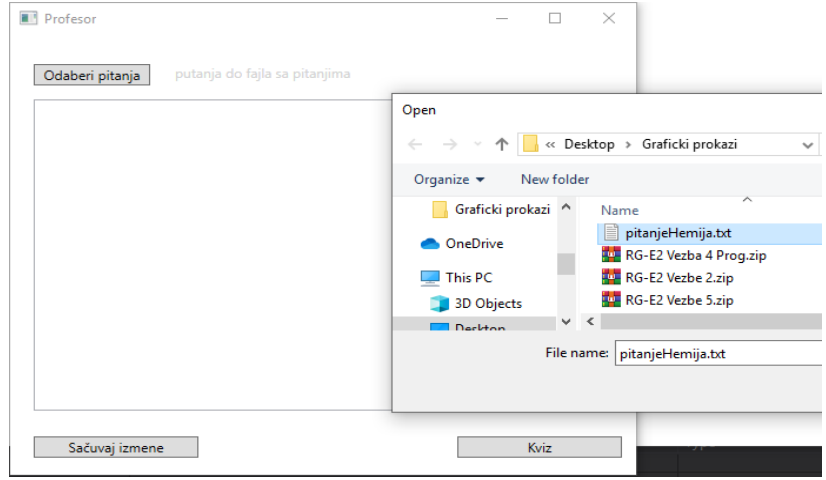

Slika 5.2

Postoi mogućnost da se uveze fajl sa pitanjima da bi olakšali profesoru posao (Slika 5.2). Ako je fajl koji je učitan kao na slici 5.3, isparsiran po pravilima profesor će dobiti poruku da je sve u redu i da će moći da pristupi kvizu. Na osnovu (Slike 5.3) vidi se da u fajlu moramo staviti i koji je tačan odgovor. Moguće je ručno promeniti 
u fajlu odgovor kada se učita. Brojevi nam govore koji redni broj ponuđenog odgovora je tačan. Dok u pozadini se fajl parsira uz proveru tako da nije moguće snimiti fajl ako profesor zaboravi prilikom pravljenja pitanja i ponuđenih odgovora da napiše koji je tačan odgovor. Neophodno je da imamo postavljeno pitanje sa upitnim znakom "?" i rednim brojem pitanja.

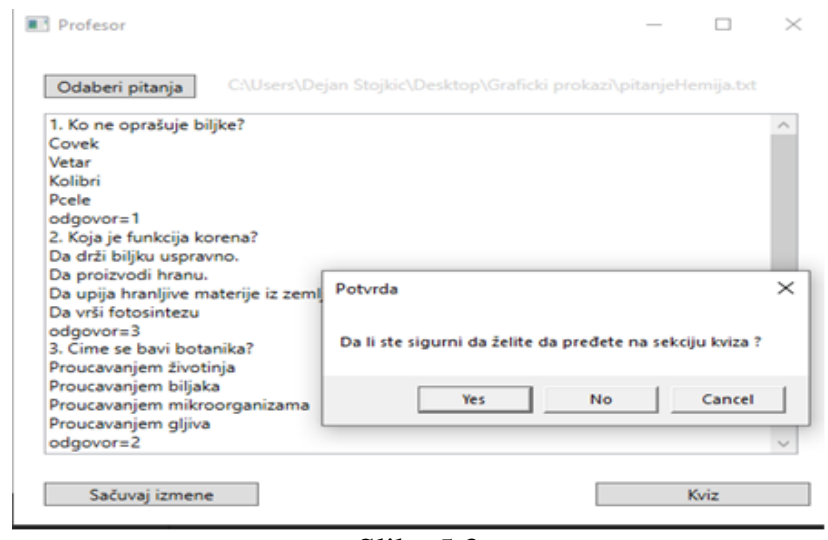

Slika 5.3

Naravnu u ovom režimu na većinu akcija imamo dodatne dijaloge za potvrdu akcija, zbog moguće nepažnje , uz naravno nedozvoljavanje prelaska u narednu sekciju ako parsiranje fajla nije u potpunosti ispoštovalo pravila.

Svako pitanje poseduje četiri ponuđena odgovora. Gde korisnik ima parvo da odabere koji je tačan odgovor, dodatna opcija je takava da ako je kviz u režimu učenja korisniku se neće postaviti naredno pitanje sve dok ne da tačan odgovor na postavljeno pitanje. Ako se kviz ne nalzi u tom režimu korisnik bez obzira na ispravnost odgovora dobija naredno pitanje. Nakon tačnog odgovora vrši se kretanje figure zbog domenskog znanja figura koja se kreće po mapi zavisi od domena u ovo slučaju na pitanje iz biologije 3D objekat koji služi za kretanje je drvo umesto robota (slika 5.4).

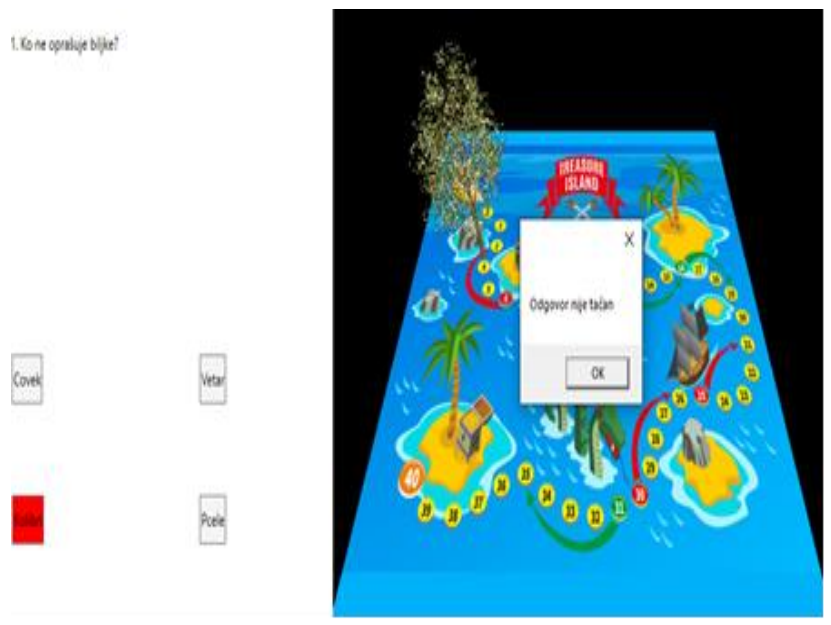

Slika 5.4

\section{ZAKLJUČAK}

Zadatak projekta jeste konstrukcija kviza domenskog znanja uz pomoć Sphero SPRK+ robota i pandam njemu konstrukcija desktop igre. Deci je potrebno kvalitetno naučno iskustvo tokom njihovog ranog djetinjstva.
Nauka i pismenost pruža sistematski, obrazovni okvir, zasnovan na standardima kao što su nastavni plan, program i kvalitetni nastavnici. Ovaj program takođe efikasno integriše tekst, ilustracije i dijagrame instrukcija zasnovana na istraživnju.

Cilj ove aplkacije jeste učenje određene oblasti kroz igru, gde će učenik videti posledice svojih odgovora u realnom svetu. Aplikacija pomaže profesoru i učeniku jer profesor može lakše i objektivnije da odredi znanje učnika odnosno da ih ocjeni za prikazano znanje. Nakon primene u osnovnoj školi zaključak je da su učenici vidno zainteresovaniji i motivisaniji za učenje. Kao što smo videli kroz brojna istraživanje svetski poznatih psihologa da je motivacija najveći problem u mlađim uzrastima i da ona najviše koči intelektualno razvijanje deteta. Možemo reći da je projekat uprkos tehničkim problemima ipak uspeo u realnoj primeni i dao pozitivne rezultate.

\section{LITERATURA}

[1] Eshach \& Fried 2005; Watters, Diezmann, Grieshaber, \& Davis, 2000 „Enhancing Science Education for Young Children: A Contemporary Initiative" from, https://www.researchgate.net/publication/27464158_Enhancin g_Science_Education_for_Young_Children_A_Contemporary Initiative

[2] Eshach, H., \& Fried MN; ,Should science be taught in early childhood"; (2005)

[3] Kuhn \& Pearsall,; Kuhn \& Schauble, \& GarciaMilla, "Contemporary Perspectives and Research on Early Childhood Education"; (2000)

[4] Sphero robot: https://sdk.sphero.com/sphero-robotbasics/what-is-sphero (pristupljeno u julu 2019.)

[5] Bcrypt algoritam, https://thehackernews.com/2014/04/securing-passwords-withbcrypt-hashing.html (pristupljeno u julu 2019.)

[6] Wikipedia contributors. (2018, March 26).React. In Wikipedia, The Free Encyclopedia. Retrieved 20:07, Jun 13, 2019, from

https//:sr.wikipedia.org/wiki/React_(библиотека_за_JavaScri pt)\#cite_note-7

\section{Kratka biografija:}

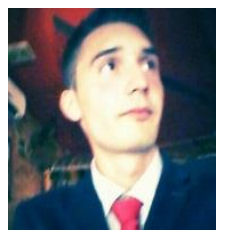

Dejan Stojkić rođen je u Zvorniku 1995. god. upisuje Gimnaziju Petar Kočić u Zvorniku završava 2014. godine kao dobitnik Vukove diplome. Fakultet tehničkih nauka u Novom Sadu je upisao 2014. godine. Stipendista softverske kompanije Naovis tokom studija. Po završetku osnovnih studija 2018. upisuje master na smeru Inteligentni sistemi i istovremeno radi na FTN-u kao saradnik u nastavi i kao profesor u srednjoj školi Jovan Jovanović Zmaj u Novom Sadu. 